\title{
NMR structural elucidation of the arabinan from Prunus dulcis immunobiological active pectic polysaccharides
}

\author{
Fernando Dourado a, Susana M. Cardoso b,c, Artur M.S. Silva ${ }^{\text {b, }}$ \\ Francisco M. Gama ${ }^{a}$, Manuel A. Coimbra ${ }^{\text {b,* }}$ \\ a Centro de Engenharia Biológica - Largo do Paço, Universidade do Minho, 4710-057 Braga, Portugal \\ ${ }^{\mathrm{b}}$ Departamento de Química, Universidade de Aveiro, P-3810-193 Aveiro, Portugal \\ ${ }^{\mathrm{c}}$ Escola Superior Agrária, Instituto Politécnico de Bragança, P-5301-855 Bragança, Portugal
}

Received 28 December 2005; received in revised form 10 February 2006; accepted 13 February 2006

Available online 12 May 2006

\begin{abstract}
The structure of the arabinan moiety of a purified arabinan-rich pectic polysaccharide from the cell walls of Prunus dulcis seeds was investigated by NMR spectroscopy. This polymer, which is able to induce a lymphocyte stimulatory effect, had an arabinan glycosidiclinkage composed of T-Araf: $(1 \rightarrow 5)$-Araf: $(1 \rightarrow 3,5)$-Araf: $(1 \rightarrow 2,3,5)$-Araf in the relative proportions of approximately $3: 2: 1: 1$. Based on the ${ }^{1} \mathrm{H},{ }^{13} \mathrm{C}$, COSYPR, $g \mathrm{HSQC}$ and $g \mathrm{HMBC}$ spectra of analysed arabinan, a tentative structure is presented, showing that it is composed by a very branched and, possibly, repetitive structure of seven residues. The observed $(1 \rightarrow 5)$ direct linkage between $(1 \rightarrow 2,3,5)$ Ara $f$ and $(1 \rightarrow 3,5)$-Ara $f$ residues support the occurrence of these contiguous branched residues in the arabinan backbone.
\end{abstract}

(C) 2006 Elsevier Ltd. All rights reserved.

Keywords: Arabinan; Prunus dulcis; Almond; NMR; Structure

\section{Introduction}

Almonds are one of the most popular tree nuts on a worldwide basis. These seeds are typically used in a variety of processed foods, notably in bakery and confectionery products (Young \& Cunningham, 1991). In previous work, the cell wall polysaccharides from the Portuguese almond seed (Prunus dulcis) were sequentially extracted and the sugar composition of each fraction was determined (Dourado, Barros, Mota, Coimbra, \& Gama, 2004a). An acidic arabinan-rich pectic polysaccharide was purified by anionexchange chromatography from the $4 \mathrm{M} \mathrm{KOH}+$ borate crude extract. Immunobiological analyses showed that it was able to induce murine lymphocyte stimulatory effect, as evaluated by the in vitro and in vivo expression of lymphocyte activation markers and spleen mononuclear cells

\footnotetext{
* Corresponding author. Tel.: +351 234370 706; fax: +351 234370084 . E-mail address: mac@dq.ua.pt (M.A. Coimbra).
}

culture proliferation (Dourado et al., 2004b). This arabinan-rich pectic polysaccharide had an apparent molecular mass of $762 \mathrm{kDa}$ and, by methylation analysis, the relative proportions of the arabinosyl linkages were shown to be, approximately, 3:2:1:1 for T-Araf:(1 $\rightarrow 5)$-Araf:( $(\rightarrow 3,5)$ Araf: $(1 \rightarrow 2,3,5)$-Araf.

Arabinans are present in the primary cell walls of different parts of plants of many families notably in seeds, fruits and roots, usually as pectic polysaccharide side-chains (Brett \& Waldron, 1996; Cardoso, Silva, \& Coimbra, 2002; Eriksson, Andersson, Westerlund, \& Åman, 1996; Navarro, Cerezo, \& Stortz, 2002; Petkowicz, Sierakowski, Ganter, \& Reicher, 1998). The arabinosyl-linkage composition of arabinans has been reported to consist of a $\alpha$ $(1 \rightarrow 5)$-Araf backbone substituted at $O-2$ and/or $O-3$ by other Araf residues (Brett \& Waldron, 1996). The degree of branching, as well as the degree of polymerisation, may vary significantly, depending on the source of the arabinan. Also, as observed for olive fruit, the degree of polymerisation of the arabinans vary with the stage of rip- 
ening of the fruit (Ferreira, Mafra, Soares, Evtuguin, \& Coimbra, 2006).

The side-chains of arabinans consist mainly of $\alpha$ $(1 \rightarrow 3)$-Ara $f$ residues. However, less common structures have been identified, such as the predominant arabinosyl residues substituted at both $O-2$ and $O-5$, isolated from dehulled rapeseed (Eriksson et al., 1996). While terminal arabinosyl residues mostly occur as furanoses, pyranose forms were also identified in arabinans from Cajanus cajan cotyledon (Swamy \& Salimath, 1991). Also, although most of the arabinofuranosyl residues have an $\alpha$ anomeric configuration, a T- $\beta$-Ara $f$ residue was detected in an arabinan from olive pectic polysaccharides (Cardoso et al., 2002; Coimbra, Delgadillo, Waldron, \& Selvendran, 1996).

To learn more about the structure of the $P$. dulcis immunobiological active pectic polysaccharide, this paper describes the structure of its arabinan moiety, investigated by NMR spectroscopy.

\section{Materials and methods}

\subsection{Preparation and isolation of the material}

The arabinan-rich pectic polysaccharide from the cell wall material of $P$. dulcis seeds was obtained as previously described (Dourado et al., 2004a; Dourado et al., 2004b). Briefly, a crude extract from a $4 \mathrm{M} \mathrm{KOH}+\mathrm{H}_{3} \mathrm{BO}_{3}$ treatment was purified by anion-exchange chromatography, yielding two sugar-rich fractions, one neutral and one acidic. The acidic fraction, which represented $50 \%$ of almond cell wall material, was composed by $53 \mathrm{~mol} \%$ of Ara, $28 \mathrm{~mol} \%$ of galacturonic acid, $11 \mathrm{~mol} \%$ of $\mathrm{Xyl}, 4 \mathrm{~mol} \%$ of Gal and $3 \mathrm{~mol} \%$ of Rha. This fraction, containing $99.5 \%$ of sugars, was used for the NMR experiments.

\subsection{NMR studies}

${ }^{1} \mathrm{H}$ and ${ }^{13} \mathrm{C}$ NMR spectra were recorded in $\mathrm{D}_{2} \mathrm{O}$ on a Bruker Avance 500 spectrometer operating at 500.13 and 125.77 MHz, respectively; the chemical shifts are expressed in $\delta(\mathrm{ppm})$ values relative to TSS as external reference. 2D COSYPR (homonuclear shift correlation with presaturation during relaxation delay) spectrum was recorded with 200 transients over 256 increments (zero-filled to $1 \mathrm{~K}$ ) and $1 \mathrm{~K}$ data points with spectral widths of $1200 \mathrm{~Hz}$. The repetition time was $1.8 \mathrm{~s}$. The data were processed in the absolute value mode. The phase sensitive ${ }^{1} \mathrm{H}$-detected $\left({ }^{1} \mathrm{H},{ }^{13} \mathrm{C}\right)$ $g$ HSQC (heteronuclear single quantum coherence, using gradient pulses for selection) spectrum was recorded with 200 transients over 256 increments (zero-filled to $1 \mathrm{~K}$ ) and $1 \mathrm{~K}$ data points with spectral widths of $1280 \mathrm{~Hz}$ in $\mathrm{F}_{2}$ and $7000 \mathrm{~Hz}$ in $\mathrm{F}_{1}$. The repetition time was $2.3 \mathrm{~s}$. A cosine multiplication was applied in both dimensions. The delays were adjusted according to a coupling constant ${ }^{1} J(\mathrm{CH})$ of $149 \mathrm{~Hz}$. The $g \mathrm{HMBC}$ (heteronuclear multiple quantum coherence, using gradient pulses for selection) spectrum was recorded with 200 transients over 256 increments (zero-filled to $1 \mathrm{~K}$ ) and $1 \mathrm{~K}$ data points with spectral widths of $1280 \mathrm{~Hz}$ in $F_{2}$ and $7000 \mathrm{~Hz}$ in $F_{1}$. The repetition time was $2.3 \mathrm{~s}$. A sine multiplication was applied in both dimensions. The low-pass $J$-filter of the experiment was adjusted for an average coupling constant ${ }^{1} J(\mathrm{CH})$ of $149 \mathrm{~Hz}$ and the long-range delay utilised to excite the heteronuclear multiple quantum coherence was optimised for $7 \mathrm{~Hz}$.

\section{Results and discussion}

\section{1. ${ }^{13}$ C NMR}

Fig. 1 shows the ${ }^{13} \mathrm{C}$ NMR spectrum of the purified arabinan-rich pectic polysaccharide. Based on spectral data from arabinans (Capek, Toman, Kardosova, \& Rosik, 1983; Cardoso et al., 2002; Habibi, Mahrouz, \& Vignon, 2005; Joseleau, Chambat, \& Lanvers, 1983; Swamy \& Salimath, 1991; Vignon, Heux, Malainine, \& Mahrouz, 2004), arabinoxylans (Broberg, Thomsen, \& Duus, 2000; Nandini \& Salimath, 2002; Roubroeks, Andersson, \& Åman, 2000), and pectins (Habibi, Heyraud, Mahrouz, \& Vignon, 2004; Pressey \& Himmelbach, 1984; Ryden, Colquhoun, \& Selvendran, 1989), ${ }^{13} \mathrm{C}_{1}$ signals were assigned to the following $\alpha$-L-arabinofuranosyl residues: T- $\alpha$-L-Ara $f,(1 \rightarrow 5)-\alpha$-LAraf, $(1 \rightarrow 3,5)$ - $\alpha$-L-Ara $f$ and $(1 \rightarrow 2,3,5)$ - $\alpha$-L-Araf $f$ (Fig. 1 and Table 1). These results were in agreement with the results obtained by methylation analysis for this sample (Dourado et al., 2004b). Although the arabinan-rich extract contained some xylose, rhamnose, galacturonic acid and galactose (Dourado et al., 2004b), no major ${ }^{13} \mathrm{C}_{1}$ signals were observed for these residues. This may occur due to the lower degree of freedom of galacturonic acid residues of the pectic polysaccharide backbone (Keenan, Belton, Matthew, \& Howson, 1985; Pressey \& Himmelbach, 1984; Schols, Posthumus, \& Voragen, 1990) when compared to the arabinofuranosyl units and to the scarceness of the other sugar residues. According to this, the low intense and broad peaks at $\delta_{\mathrm{C}}=70.9,72.3,100.7$ and 102.0 should be assigned to the GalA (Coimbra et al., 1996; Habibi et al., 2004) and Xyl residues (Coimbra, Waldron, \& Selvendran, 1994; Shatalov, Evtuguin, \& Neto, 1999). The absence of a well-defined signal at $\delta_{\mathrm{C}}=104$ (Coimbra et al., 1996; Cardoso et al., 2002) indicated that no T- $\beta$-Ara $f$ residues were present in the arabinan structure.

In accordance with Nandini and Salimath (2002), distinct C-1 signals (110.0 and 109.8) were ascribed to T- $\alpha$ L-Araf. These terminal residues must be differentially linked to the backbone of the arabinan chain, as will be discussed bellow. To facilitate the discussion of the 2D NMR results, Fig. 2 shows a proposed structure for the arabinan moiety. Besides the arabinosyl residues, no other sugar residues were considered to occur as constituents of these side chains. The possible occurrence of uronic acids as terminal residues of these arabinans would result in intense peaks, not observed in the NMR spectra. For example, in olive pulp, the occurrence of a $\beta$-terminal arabinosyl residue 

A: 5$)-\operatorname{Araf}-(1 \rightarrow 1$
B: 3,5$)-\operatorname{Araf}-(1 \rightarrow 1$
C: $\operatorname{Araf}-(1 \rightarrow \quad 1$
D: Araf- $(1 \rightarrow \quad 1$
E: $2,3,5)-\operatorname{Ara} f-(1 \rightarrow 1$

5

5

5

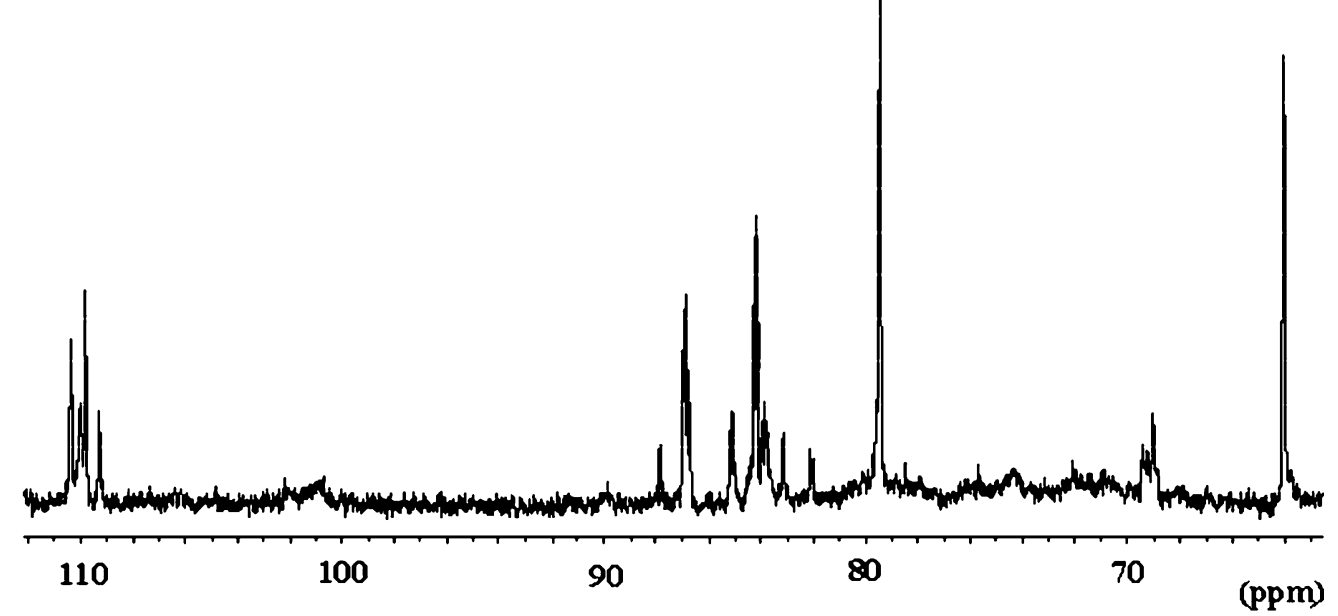

Fig. $1 .{ }^{13} \mathrm{C}$ NMR spectrum of almond arabinan. The numbers above each peak refer to the carbon atoms positioned across the Ara residues, listed to left, according to the chemical shifts given in Table 1.

Table 1

Peak assignments of ${ }^{13} \mathrm{C}$ and ${ }^{1} \mathrm{H}$ NMR spectra of almond arabinan $(\delta, \mathrm{ppm})$

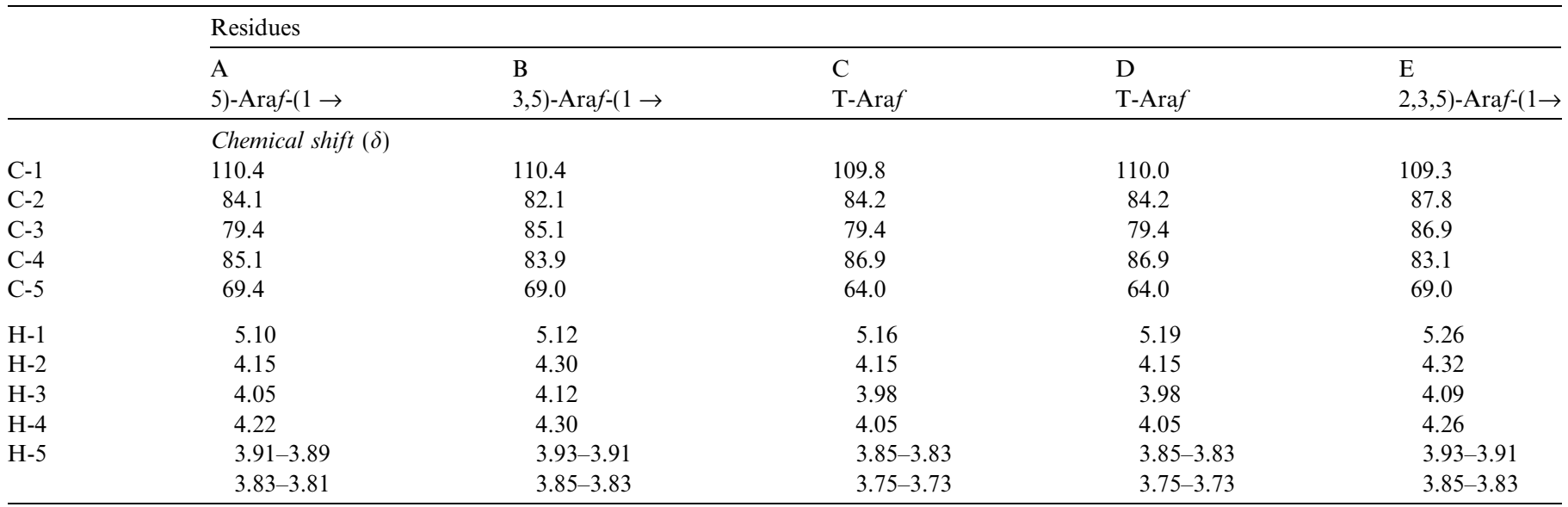

was shown to be identified by a very distinct signal, from all other $\alpha$-terminal arabinosyl residues (Cardoso et al., 2002).

Having in mind that other structural arrangements are possible, the structure here presented agrees well with data from the methylation analysis (Dourado et al., 2004b) and ${ }^{13} \mathrm{C}$ NMR.

\section{2. $\left({ }^{1} \mathrm{H},{ }^{13} \mathrm{C}\right) \mathrm{gHSQC}$}

The one-bond correlation of the ${ }^{13} \mathrm{C}$ and ${ }^{1} \mathrm{H}$ spectrum (Fig. 3) showed five cross peaks in its anomeric region. The $\mathrm{C}-1$ signal at $\delta_{\mathrm{C}-1}=110.4$, assigned to the $(1 \rightarrow 5)-\alpha$ L-Ara $f$ and $(1 \rightarrow 3,5)$ - $\alpha$-L-Ara $f$ (residues $\mathrm{A}$ and $\mathrm{B}$, respec- tively, Fig. 2) showed cross-peaks with $\mathrm{H}-1$ resonances at $\delta_{\mathrm{H}-1}=5.10$ and $\delta_{\mathrm{H}-1}=5.12$. These ${ }^{1} \mathrm{H}$ chemical shifts, as observed by Cardoso et al. (2002), were attributed to H-1 of residue $\mathrm{A}$ and $\mathrm{B}$, respectively.

The $\mathrm{H}-1$ at $\delta_{\mathrm{H}-1}=5.16$ and $\delta_{\mathrm{H}-1}=5.19$ were assigned to T- $\alpha$-L-Ara $f$ (residues C and D, Fig. 2) since they were correlated to the C-1 signals at $\delta=109.8$ and 110.0 , respectively. However, it is worthy to note that $\mathrm{C}-1$ of residue $\mathrm{D}$ was also correlated with the $\mathrm{H}-1$ resonance at $\delta_{\mathrm{H}-1}=5.20$. This shoulder in the $\mathrm{H}-1$ signal suggests that residue $\mathrm{D}$ can have different environments in the arabinan structure. The cross peak between $\mathrm{C}-1$ at $\delta_{\mathrm{C}-1}=109.3$ and the proton resonance at $\delta_{\mathrm{H}-1}=5.26$ allowed to assign the $\mathrm{H}-1$ resonance of $(1 \rightarrow 2,3,5)-\alpha-$-L-Ara $f$ (residue E, Fig. 2). 


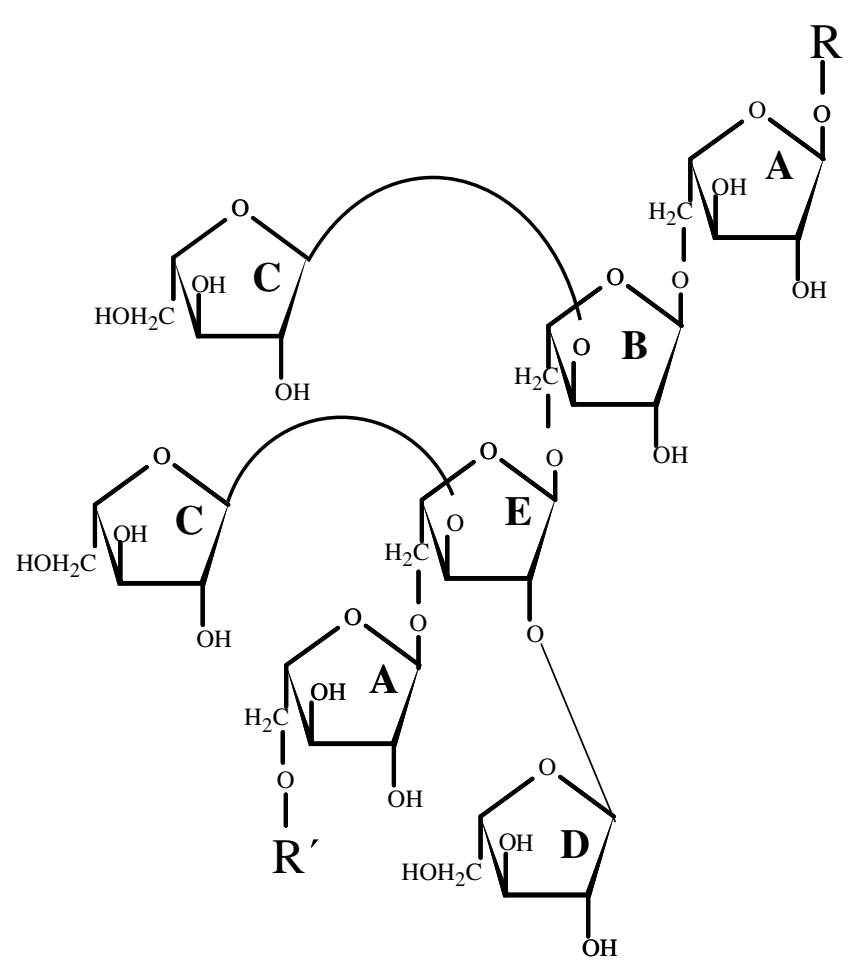

Fig. 2. Proposed structure for the arabinan moiety of the arabinan-rich pectic polysaccharide from the cell walls of $P$. dulcis seed. R, possible linkage to the pectic polysaccharide backbone; $\mathrm{R}^{\prime}$, terminal residue or repetitive arabinan structure.

The integration of the ${ }^{1} \mathrm{H}$ NMR spectra for the assigned $\mathrm{H}-1$ is in accordance with the relative proportion of $3: 2: 1: 1$ for the T-Araf:(1 $\rightarrow 5)$-Araf: $(1 \rightarrow 3,5)$-Araf: $(1 \rightarrow 2,3,5)$ Araf residues estimated previously by methylation analysis (Dourado et al., 2004b).

\section{3. $2 D$ COSYPR}

From the COSY spectrum shown in Fig. 4, it was possible to correlate the $\mathrm{H}-1$ of residue $\mathrm{A}\left(\delta_{\mathrm{H}-1}=5.10\right)$ with $\mathrm{H}-2$ $\left(\delta_{\mathrm{H}-2}=4.15\right)$ and $\mathrm{H}-2$ with $\mathrm{H}-3\left(\delta_{\mathrm{H}-3}=4.05\right)$. These results and the analysis of the $g \mathrm{HSQC}$ spectrum allowed to attribute the C-2 and C-3 of ( $\rightarrow 5$ )- $\alpha$-L-Ara $f$ (residue A) to $\delta_{\mathrm{C}-2}=84.1$ and $\delta_{\mathrm{C}-3}=79.4$, respectively.

The $\mathrm{H}-1$ of residue $\mathrm{B}\left(\delta_{\mathrm{H}-1}=5.12\right)$ was correlated with $\mathrm{H}-2\left(\delta_{\mathrm{H}-2}=4.30\right)$ and $\mathrm{H}-2$ with $\mathrm{H}-3\left(\delta_{\mathrm{H}-3}=4.12\right)$. The corresponding $\mathrm{C}-2$ and $\mathrm{C}-3$ were assigned, in the $g \mathrm{HSQC}$ spectrum, to $\delta_{\mathrm{C}-2}=82.1$ and $\delta_{\mathrm{C}-3}=85.1$, respectively. The assignments of $\mathrm{H}-2, \mathrm{H}-3, \mathrm{C}-2$ and $\mathrm{C}-3$ of the remaining residues (Table 1) were made by a similar procedure. The $\mathrm{H}-1$ of the T- $\alpha$-L-Ara $f$, residues $\mathrm{C}\left(\delta_{\mathrm{H}-1}=5.16\right)$ and $\mathrm{D}\left(\delta_{\mathrm{H}-1}=\right.$ $5.19)$, were both correlated with $\mathrm{H}-2\left(\delta_{\mathrm{H}-2}=4.15\right)$ and the $\mathrm{H}-2$ with $\mathrm{H}-3\left(\delta_{\mathrm{H}-3}=3.98\right)$. The $\mathrm{C}-2$ and $\mathrm{C}-3$ of both residues shared a common signal at $\delta_{\mathrm{C}-2}=84.2$ and $\delta_{\mathrm{C}-3}=79.4$. Also, $\mathrm{H}-1$ of residue $\mathrm{E}\left(\delta_{\mathrm{H}-1}=5.26\right)$ was correlated with $\mathrm{H}-2\left(\delta_{\mathrm{H}-2}=4.32\right)$ and $\mathrm{H}-2$ to $\mathrm{H}-3\left(\delta_{\mathrm{H}-3}=4.09\right)$. The C-2 and C-3 of residue E were attributed to $\delta_{\mathrm{C}-2}=87.8$ and $\delta_{\mathrm{C}-3}=86.9$.

\section{4. $\left({ }^{1} \mathrm{H},{ }^{13} \mathrm{C}\right) \mathrm{gHMBC}$}

The C-4 resonances of $(1 \rightarrow 3,5)$ - $\alpha$-L-Araf $f$ residue B), $(1 \rightarrow 5$ )- $\alpha$-L-Araf $f$ residue A) and T- $\alpha$-L-Ara $f$ (residues C and D) were assigned by the analysis of the $g \mathrm{HMBC}$ spectrum (Fig. 5) and from the data published by Cardoso et al. (2002). These residues showed cross-peaks between H-1 and C-4 at $\delta_{\mathrm{C}-4}=83.9,85.1$, and 86.9 , respectively. These results and the analysis of the $g \mathrm{HSQC}$ spectrum allowed to assign $\mathrm{H}-4$ of residue $\mathrm{B}$ to $\delta_{\mathrm{H}-4}=4.30$, of residue $\mathrm{A}$ to $\delta_{\mathrm{H}-4}=4.22$ and of residues $\mathrm{C}$ and $\mathrm{D}$ to $\delta_{\mathrm{H}-4}=4.05$.

The C-4 of residue $\mathrm{E}$ was ascribed by a cross-peak between $\mathrm{H}-2\left(\delta_{\mathrm{H}-2}=4.32\right)$ and the resonance at $\delta_{\mathrm{C}-4}=$ 83.1, since this chemical shift was in accordance with the literature data (Broberg et al., 2000; Capek et al., 1983; Habibi et al., 2004, 2005; Swamy \& Salimath, 1991). The corresponding $\mathrm{H}-4$ resonance was ascribed in the $g \mathrm{HSQC}$ to $\delta_{\mathrm{H}-4}=4.26$. These results and the analysis of the COSY spectrum allowed to obtain $\mathrm{H}-5$ resonances for the majority of the arabinofuranosyl residues. The H-4 peak of residue A was correlated with $\mathrm{H}-5$ at $\delta_{\mathrm{H}-5}=3.91-3.89$ and 3.83-3.81. In this residue, a correlation between $\mathrm{H}-4$ and $\mathrm{H}-3\left(\delta_{\mathrm{H}-3}=4.05\right)$ is also visible by COSY. By a similar procedure, it was possible to assign $\mathrm{H}-5$ of residue $\mathrm{B}$ to $\delta_{\mathrm{H}-5}=3.93-3.91$ and $3.85-3.83$ and $\mathrm{H}-5$ of the two T- $\alpha-\mathrm{L}-$ Araf residues $(\mathrm{C}$ and $\mathrm{D})$ to the regions $\delta_{\mathrm{H}-5}=3.85-3.83$ and 3.75-3.73.

From the analysis of the $g \mathrm{HSQC}$ spectrum, the C-5 of T$\alpha$-L-Ara $f$ residues $(\mathrm{C}$ and $\mathrm{D})$ were then assigned at $\delta_{\mathrm{C}-5}=$ 64.0, the C-5 of residue B was assigned at $\delta_{\mathrm{C}-5}=69.0$ and the $\mathrm{C}-5$ of residue $\mathrm{A}$ was assigned at $\delta_{\mathrm{C}-5}=69.4$. It should be noted that, in this work, the $\mathrm{H}-5$ and $\mathrm{C}-5$ resonances of residues $\mathrm{A}$ and $\mathrm{B}$ (Table 1) are swapped, when compared to the results from Cardoso et al. (2002). As the chemical shifts here presented were obtained from the COSY and HSQC spectra, while the other ones were only tentatively assigned based on literature data, these may be the correct ones. The $\mathrm{C}-5$ of residue $\mathrm{E}$ was ascribed, in the $g \mathrm{HMBC}$ spectrum, by a cross peak between $\mathrm{H}-4$ and the resonance at $\delta_{\mathrm{C}-5}=69.0$. From the $g \mathrm{HSQC}$, the $\mathrm{H}-5$ of this residue was assigned to $\delta_{\mathrm{H}-5}=3.93-3.91$ and 3.85-3.83.

As previously mentioned, the T- $\alpha$-L-Ara $f$ residues $(\mathrm{C}$ and $\mathrm{D})$ were proposed to be differentially linked to the backbone of the arabinan chain. Their linkage position was clarified by interpretation of the $g \mathrm{HMBC}$ spectrum. The $\mathrm{H}-1$ at $\delta_{\mathrm{H}-1}=5.16$ (ascribed to residue $\mathrm{C}$ ) was correlated with $\mathrm{C}-4$ of residue $\mathrm{E}\left(\delta_{\mathrm{C}-4}=83.1\right)$, suggesting that residue $\mathrm{C}$ must be linked through $O-3$ to residue $\mathrm{E}$ (Fig. 2). This result was also supported by the cross peaks between $\mathrm{H}-4$ of residue $\mathrm{E}\left(\delta_{\mathrm{H}-4}=4.26\right)$ and $\mathrm{H}-2$ of residue $\mathrm{E}\left(\delta_{\mathrm{H}-2}=\right.$ $4.32)$ with the anomeric carbon of residue $\mathrm{C}\left(\delta_{\mathrm{C}-1}=109.8\right)$. Also, the observed cross peak between $\mathrm{H}-3$ of residue $\mathrm{E}$ $\left(\delta_{\mathrm{H}-3}=4.09\right)$ and the anomeric carbon of residue $\mathrm{D}$ $\left(\delta_{\mathrm{C}-1}=110.0\right)$ suggested that residue $\mathrm{D}$ corresponds to the T- $\alpha$-L-Araf unit that is linked to residue E, through $O-2$. Attending to the relative proportions of the arabinofuranosyl units (approximately 3:2:1:1 for residues 


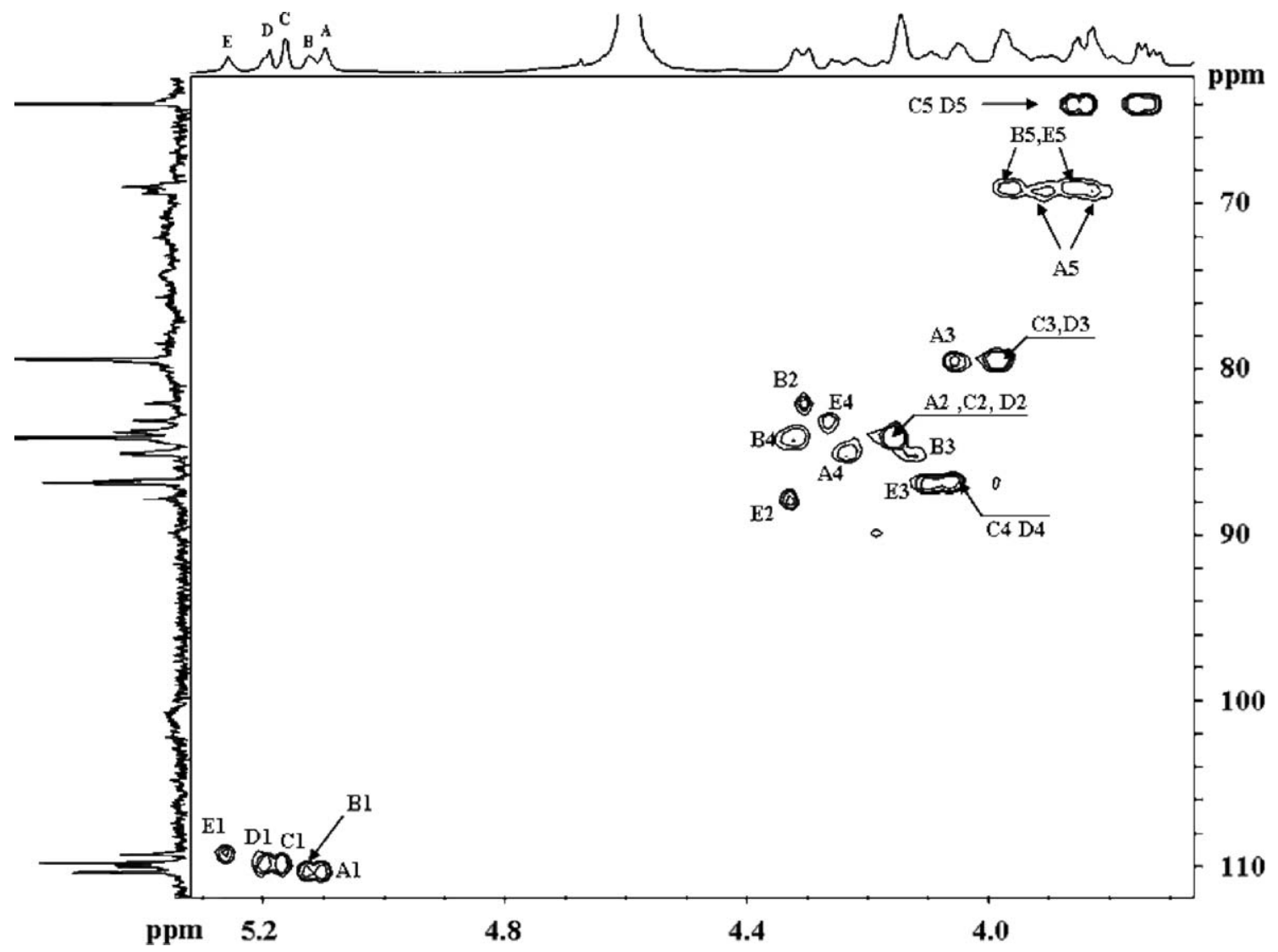

Fig. 3. $\left({ }^{1} \mathrm{H},{ }^{13} \mathrm{C}\right) \mathrm{gHSQC}$ spectrum of almond arabinan. Capital letters represent the Ara residues according to Fig. 2. Each number stands for the carbon position giving rise to the cross peak, according to the chemical shifts given in Table 1.

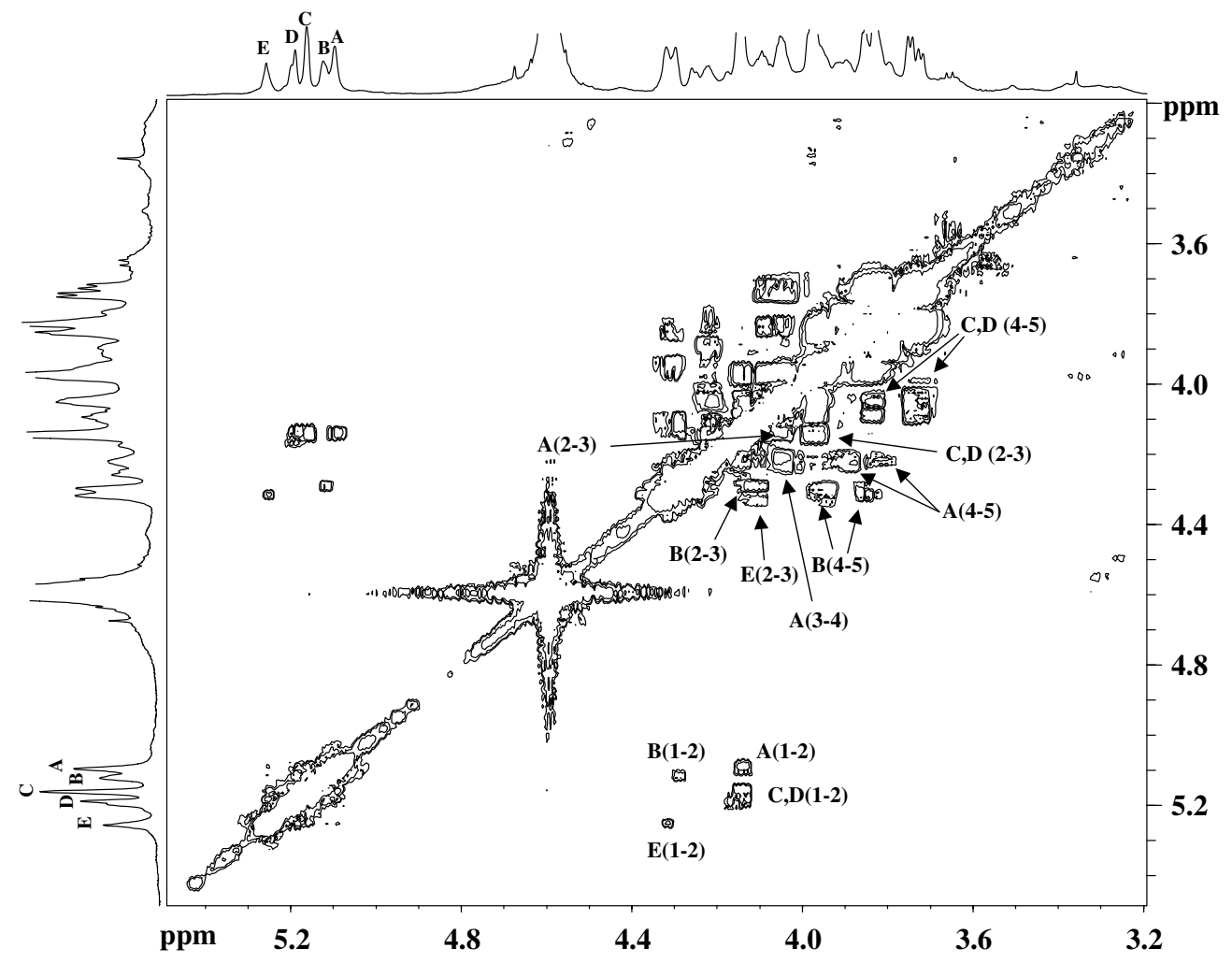

Fig. 4. 2D COSYPR spectrum of almond arabinan. Capital letters represent the Ara residues according to Fig. 2. 


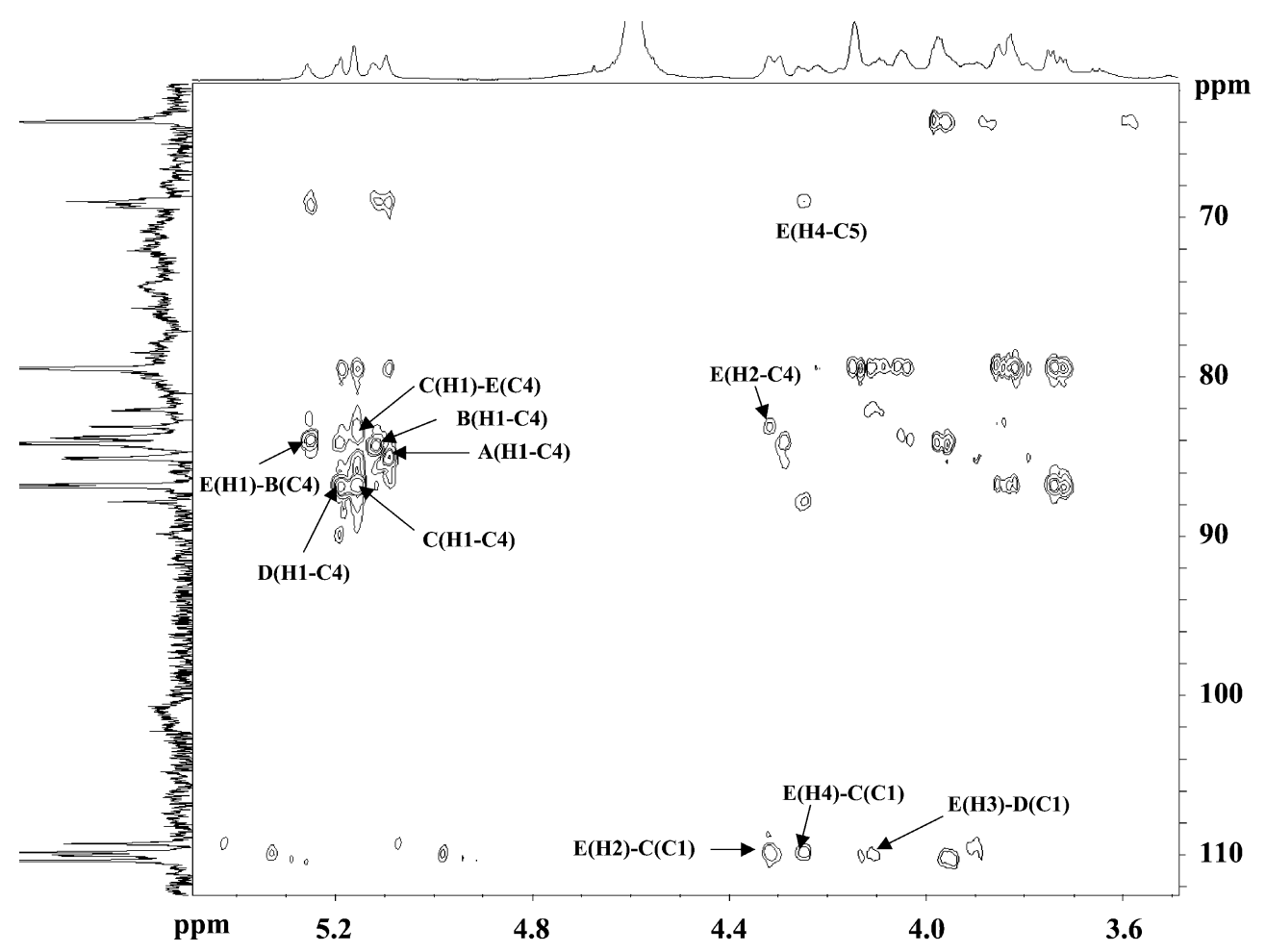

Fig. 5. $\left({ }^{1} \mathrm{H},{ }^{13} \mathrm{C}\right) \mathrm{gHMBC}$ spectrum of almond seed arabinan. Capital letters represent the Ara residues according to Fig. 2.

$\mathrm{C}+\mathrm{D}: \mathrm{A}: \mathrm{B}: \mathrm{E})$ and to the relative intensities of the ${ }^{1} \mathrm{H}$ areas of residues $\mathrm{C}$ and $\mathrm{D}$ (approximately $2: 1$ ), another residue $\mathrm{C}$ was ascribed to the T- $\alpha$-L-Ara $f$ unit that is linked to $O-3$ of residue $\mathrm{B}$.

Additional information on the arabinan structure was obtained by the correlation peak between the anomeric proton of residue $\mathrm{E}\left(\delta_{\mathrm{H}-1}=5.26\right)$ and $\mathrm{C}-4$ of residue $\mathrm{B}$ $\left(\delta_{\mathrm{C}-4}=83.9\right)$. This result suggested the occurrence of contiguous branched residues in the arabinan backbone (Fig. 2). Although no published information regarding similar observations were found, the existence of blocks in the arabinan chain could partially explain the presence of a shoulder in the $\mathrm{H}-1$ resonance of residue D.

\section{Conclusions}

In sum, by NMR spectroscopy, the structure of the arabinan moiety of a purified arabinan-rich pectic polysaccharide from the cell walls of $P$. dulcis seeds was elucidated. The arabinan was composed by a very branched and, possibly, repetitive structure of seven residues, with a $(1 \rightarrow 5)$ Araf backbone. In it, contiguous $(1 \rightarrow 3,5)$-Ara $f$ and $(1 \rightarrow 2,3,5)$-Ara $f$ residues can occur. The T- $\alpha$-L-Ara $f$ residues were linked through $O-3$ and $O-2$ of the $(1 \rightarrow 2,3,5)$ Araf $f$ residues and also through $O-3$ of the $(1 \rightarrow 3,5)$-Araf. A tentative structure of this arabinan is presented in Fig. 2.

\section{Acknowledgements}

F. Dourado thanks FCT (Portugal) for the Doctoral Grant PRAXIS XXI/BD/18401/98. The authors also acknowledge FCT, Portugal, and the University of Aveiro for funding the Research Unit 62/94 "Química Orgânica, Produtos Naturais e Agro-Alimentares."

\section{References}

Brett, C. T., \& Waldron, K. W. (1996). Physiology and biochemistry of plant cell walls (2nd ed.). London: Chapman \& Hall.

Broberg, A., Thomsen, K. K., \& Duus, J. O. (2000). Application of nanoprobe NMR for structure determination of low nanomole amounts of arabinoxylan oligosaccharides fractionated by analytical HPAECPAD. Carbohydrate Research, 328, 375-382.

Capek, P., Toman, R., Kardosova, A., \& Rosik, J. (1983). Polysaccharides from the roots of the marsh mallow (Althaea officinalis L.): Structure of an arabinan. Carbohydrate Research, 117, 133-140.

Cardoso, S. M., Silva, A. M. S., \& Coimbra, M. A. (2002). Structural characterisation of the olive pomace pectic polysaccharide arabinan side chains. Carbohydrate Research, 337, 917-924.

Coimbra, M. A., Delgadillo, I., Waldron, K. W., \& Selvendran, R. R. (1996). Isolation and analysis of cell wall polymers from olive pulp. In H. F. Linskens \& J. F. Jackson (Eds.). Modern methods of plant analysis (Vol. 17, pp. 19-44). Berlin: Springer.

Coimbra, M. A., Waldron, K. W., \& Selvendran, R. R. (1994). Isolation and characterisation of cell wall polymers from olive pulp (Olea europaea L.). Carbohydrate Research, 252, 245-262.

Dourado, F., Barros, A., Mota, M., Coimbra, M. A., \& Gama, F. M. (2004a). Anatomy and cell wall polysaccharides of almond (Prunus dulcis D.A. Weeb) seeds. Journal of Agricultural and Food Chemistry, 52, 1364-1370.

Dourado, F., Madureira, P., Carvalho, V., Coelho, R., Coimbra, M. A., Vilanova, M., et al. (2004b). Purification, structure and immunobiological activity of an arabinan-rich pectic polysaccharide from the cell walls of Prunus dulcis seeds. Carbohydrate Research, 339, $2555-2566$.

Eriksson, I., Andersson, R., Westerlund, E., \& Åman, P. (1996). Structural features of an arabinan fragment isolated from the water- 
soluble fraction of dehulled rapeseed. Carbohydrate Research, 281, 161-172.

Ferreira, J.A., Mafra, I., Soares, M.R., Evtuguin, D.V., \& Coimbra, M.A. (2006). Dimeric calcium complexes of arabinan-rich pectic polysaccharides from Olea europaea L. cell walls. Carbohydrate Polymers in press, doi:10.1016/j.carbpol.2006.02.013.

Habibi, Y., Heyraud, A., Mahrouz, M., \& Vignon, M. R. (2004) Structural features of pectic polysaccharides from the skin of Opuntia ficus-indica prickly pear fruits. Carbohydrate Research, 339, 1119-1127.

Habibi, Y., Mahrouz, M., \& Vignon, M. R. (2005). Arabinan-rich polysaccharides isolated and characterized from the endosperm of the seed of Opuntia ficus-indica prickly pear fruits. Carbohydrate Polymers, 60, 319-329.

Joseleau, J.-P., Chambat, G., \& Lanvers, M. (1983). Arabinans from the roots of horsebean (Vicia faba). Carbohydrate Research, 122, 107-113.

Keenan, M. H. J., Belton, P. S., Matthew, J. A., \& Howson, S. J. (1985). A

${ }^{13}$ C-n.m.r. study of sugar-beet pectin. Carbohydrate Research, 138, $168-170$.

Nandini, C. D., \& Salimath, P. V. (2002). Structural features of arabinoxylans from bajira (pearl millet). Journal of Agricultural and Food Chemistry, 50, 6485-6489.

Navarro, D. A., Cerezo, A. S., \& Stortz, C. A. (2002). NMR spectroscopy and chemical studies of an arabinan-rich system from the endosperm of the seed of Gleditsia triacanthos. Carbohydrate Research, 337, $255-263$.
Petkowicz, C. L. O., Sierakowski, M. R., Ganter, J. L. M. S., \& Reicher, F. (1998). Galactomannans and arabinans from seeds of Caesalpiniaceae. Phytochemistry, 49, 737-743.

Pressey, R., \& Himmelbach, D. S. (1984). ${ }^{13}$ C-n.m.r. spectrum of a Dgalactose-rich polysaccharide from tomato fruit. Carbohydrate Research, 127, 330-333.

Roubroeks, J. P., Andersson, R., \& Åman, P. (2000). Structural features of $(1 \rightarrow 3),(1 \rightarrow 4)-\beta$-D-glucan and arabinoxylan fractions isolated from rye bran. Carbohydrate Polymers, 42, 3-11.

Ryden, P., Colquhoun, I. J., \& Selvendran, R. R. (1989). Investigation of structural features on the pectic polysaccharides of onion by ${ }^{13} \mathrm{C}-\mathrm{n} . \mathrm{m} . \mathrm{r}$. spectroscopy. Carbohydrate Research, 185, 233-237.

Schols, H. A., Posthumus, M. A., \& Voragen, A. G. J. (1990). Hairy (ramified) regions of pectins. 1. Structural features of hairy regions of pectins isolated from apple juice produced by the liquefaction process. Carbohydrate Research, 206, 117-129.

Shatalov, A. A., Evtuguin, D. V., \& Neto, C. P. (1999). (2-O- $\alpha$-DGalactopyranosyl-4- $O$-methyl- $\alpha$-D-glucurono)-D-xylan from Eucaliptus globulus Labill. Carbohydrate Research, 320, 93-99.

Swamy, N. R., \& Salimath, P. V. (1991). Arabinans from Cajanus cajan cotyledon. Phytochemistry, 30, 263-265.

Vignon, M. R., Heux, L., Malainine, M. E., \& Mahrouz, M. (2004). Arabinan-cellulose composite in Opuntia ficus-indica prickly pear spines. Carbohydrate Research, 339, 123-131.

Young, C. K., \& Cunningham, S. (1991). Exploring the partnership of almonds with cereal foods. Cereal Food World, 36, 412-418. 